\title{
Article \\ Re-Irradiation for Head and Neck Cancer: Cumulative Dose to Organs at Risk and Late Side Effects
}

\author{
Anna Embring 1,2,*®D, Eva Onjukka ${ }^{2,3} \mathbb{D}$, Claes Mercke ${ }^{1,2}$, Ingmar Lax ${ }^{2,3}$, Anders Berglund ${ }^{4}$, Sara Bornedal ${ }^{3}$, \\ Berit Wennberg ${ }^{3}$, Emmy Dalqvist ${ }^{3}$ and Signe Friesland ${ }^{1,2}$ \\ 1 Department of Oncology, Karolinska University Hospital, 17176 Stockholm, Sweden; \\ clas.mercke@sll.se (C.M.); signe.friesland@sll.se (S.F.) \\ 2 Department of Oncology-Pathology, Karolinska Institute, 17176 Stockholm, Sweden; \\ eva.onjukka@sll.se (E.O.); ingmar.lax@sll.se (I.L.) \\ 3 Department of Medical Radiation Physics and Nuclear Medicine, Karolinska University Hospital, \\ 17176 Stockholm, Sweden; sara.bornedal@sll.se (S.B.); berit.wennberg@sll.se (B.W.); \\ emmy.dalqvist@sll.se (E.D.) \\ 4 Epistat Epidemiology and Statistics Consulting, 75655 Uppsala, Sweden; anders.berglund@epistat.se \\ * Correspondence: anna.embring@ki.se
}

check for updates

Citation: Embring, A.; Onjukka, E.; Mercke, C.; Lax, I.; Berglund, A.;

Bornedal, S.; Wennberg, B.; Dalqvist,

E.; Friesland, S. Re-Irradiation for

Head and Neck Cancer: Cumulative Dose to Organs at Risk and Late Side Effects. Cancers 2021, 13, 3173.

https: / / doi.org/10.3390/

cancers13133173

Academic Editor: Stefan Rieken

Received: 17 May 2021

Accepted: 21 June 2021

Published: 25 June 2021

Publisher's Note: MDPI stays neutral with regard to jurisdictional claims in published maps and institutional affiliations.

Copyright: (c) 2021 by the authors. Licensee MDPI, Basel, Switzerland. This article is an open access article distributed under the terms and conditions of the Creative Commons Attribution (CC BY) license (https:/ / creativecommons.org/licenses/by/ $4.0 /)$.
Simple Summary: Local recurrences of head and neck cancer are unfortunately common and can be difficult to treat. The treatment is challenging, partly due to the location, with several important organs in the head and neck area, but also because recurrence often occurs in an area already treated with radiotherapy. It has been shown that repeat radiotherapy, re-irradiation, can offer long-lasting tumor control and sometimes even cure in selected patients. However, there is a risk of normal tissue close to the tumor being damaged by high cumulative doses of radiotherapy. In this study, we aim to establish levels of cumulative dose to specific organs that could be considered reasonably safe to deliver at re-irradiation without causing high rates of severe side effects. Increased knowledge in dose-response relationships in re-irradiation for head and neck cancer will facilitate a tailored treatment for the individual patient.

Abstract: Re-irradiation in head and neck cancer is challenging, and cumulative dose constraints and dose/volume data are scarce. In this study, we present dose/volume data for patients re-irradiated for head and neck cancer and explore the correlations of cumulative dose to organs at risk and severe side effects. We analyzed 54 patients re-irradiated for head and neck cancer between 2011 and 2017. Organs at risk were delineated and dose/volume data were collected from cumulative treatment plans of all included patients. Receiver-operator characteristics (ROC) analysis assessed the association between dose/volume parameters and the risk of toxicity. The ROC-curve for a logistic model of carotid blowout vs. maximum doses to the carotid arteries showed AUC $=0.92$ (95\% CI 0.83 to 1.00 ) and a cut-off value of $119 \mathrm{~Gy}$ (sensitivity 1.00 /specificity 0.89 ). The near-maximum dose to bones showed an association with the risk of osteoradionecrosis: AUC $=0.74$ (95\% CI 0.52 to 0.95 ) and a cut-off value of 119 Gy (sensitivity 1.00/specificity 0.52). Our analysis showed an association between cumulative dose to organs at risk and the risk of developing osteoradionecrosis and carotid blowout, and our results support the existing dose constraint for the carotid arteries of $120 \mathrm{~Gy}$. The confirmation of these dose-response relationships will contribute to further improvements of re-irradiation strategies.

Keywords: re-irradiation; cumulative dose; organs at risk; late side effects; head and neck cancer; composite DVH; carotid blowout; osteoradionecrosis

\section{Introduction}

Radiotherapy is a central component in the primary treatment of head and neck cancer (HNC). Unfortunately, local recurrences are common and can affect as many as 
24 to $50 \%$ of patients after primary treatment [1-3]. Management of HNC recurrence or second primary in a previously irradiated volume is a therapeutic challenge. Surgery is typically the treatment of choice, but the low rates of tumor control have led investigators to question whether the modest benefits outweigh the potentially increased morbidity [4]. Several studies have shown that re-irradiation can offer durable local control or even cure in selected patients [5-10]. Patients with a relatively small tumor burden and longer interval (at least six months) between irradiations could be considered for re-irradiation with curative intent, whereas patients with considerable comorbidity and/or severe toxicity following prior radiotherapy are considered less suitable for such treatment $[11,12]$. The selection of patients suitable for re-irradiation is critical, to avoid severe side effects or even treatment-related death. Several studies have proposed different tools covering patient characteristics that are of importance in the selection $[5,13,14]$, but little is published on cumulative doses to normal tissues and dose constraints in the re-irradiation setting. Most studies published on re-irradiation of HNC are relatively small retrospective studies and the definition of re-irradiation is often vague, making comparison between different studies difficult. Moreover, there are only a few studies presenting dose/volume data and the uncertainty regarding normal tissue tolerance in the re-irradiation setting prevails.

Factors that have been shown to increase the risk of serious side effects after reirradiation are: higher dose at re-irradiation [15], higher dose at primary irradiation [13], concurrent chemotherapy at re-irradiation [16,17], radiation dose to specific organs, such as the carotid arteries [18] and mandible [17], shorter time between irradiations [19], prior surgery [8] and large re-treatment volumes [20]. In contrast to patient- and diseaserelated factors, doses and volumes at re-irradiation are to some extent modifiable. A clearer understanding of normal tissue tolerance to re-irradiation and cumulative dose constraints would provide valuable tools to tailor the individual patient's treatment plan at re-irradiation and possibly improve the therapeutic ratio. Greater certainty regarding the risk of serious complications would also facilitate a well-informed choice of treatment strategy, in consultation with the patient.

Although the knowledge regarding dose constraints in $\mathrm{HNC}$ re-irradiation is generally limited, the tolerance of a few critical organs at risk (OARs) have received greater focus. An OAR that has been relatively well investigated is the spinal cord. There are published recommendations for dose constraints both in the primary setting and at re-irradiation [21,22]. Exceeding these dose constraints can result in myelopathy, a dreaded complication; fortunately, this side effect of radiotherapy is uncommon. Another dreaded and often lethal complication of HNC and/or HNC therapy is carotid blowout syndrome, in which the carotid artery or one of its major branches ruptures. Known risk factors of carotid blowout syndrome are tumor invasion of the carotid arteries, infection, surgery and high cumulative doses of radiotherapy [23]. There is no consensus regarding dose constraints for the cumulative dose to the carotid arteries. Garg et al. suggested that the risk of developing carotid blowout syndrome is higher at cumulative doses of $>120$ Gy [18], but this is based on a small sample with only one event. A third example of a side effect that can cause considerable suffering for the patient is osteoradionecrosis (ORN). Bots et al. conducted a retrospective analysis of 137 patients that had been treated with re-irradiation for HNC. In this study, eight patients developed ORN and one patient developed chondronecrosis of the larynx after re-irradiation, with a median cumulative dose of $114 \mathrm{~Gy}$ (range, 94 to 130 Gy) [17].

The aim of the current study is to generate carefully collected dose/volume data for a group of patients re-irradiated for HNC. These data will be used to explore the correlations between cumulative dose to OARs and serious side effects, in order to confirm the dose constraints for critical OARs suggested in the literature (spinal cord, carotid arteries and mandible/bony structures) and to explore additional endpoints assumed to affect the patients' quality of life: xerostomia, dysphagia, trismus, mucosal and skin toxicity. To facilitate the interpretation of the results, a strict definition of re-irradiation has been used. 


\section{Materials and Methods}

\subsection{Patients}

Fifty-four consecutive patients treated with re-irradiation for HNC in our institution between 2011 and 2017 were retrospectively analyzed. Re-irradiation was defined as having a primary treatment of $\geq 60 \mathrm{~Gy}$ and a second treatment with an overlapping volume of $\geq 40 \mathrm{~Gy}$, resulting in a volume with a cumulative dose of $\geq 100 \mathrm{~Gy}$ (V100). Participating patients, characteristics and treatment are described in full in an earlier published article [24] and tables of patient and treatment characteristics are available in Appendix A. To facilitate comparison between different fractionation schedules, all radiotherapy doses are reported in a biologically equivalent dose of 2 Gy per fraction (EQD2) using the linear-quadratic model [25] and $\alpha / \beta=3 \mathrm{~Gy}$. Dose distribution summation and analysis of dose to OARs vs. side effects was carried out for all 54 included patients. The study was approved by the National Ethical Review Authority.

\subsection{Toxicity}

Grading of ORN was carried out according to Late Effects Normal Tissue Task Force Subjective, Objective, Management, and Analytic (LENT/SOMA) scores [26]. Grading of all other acute and late toxicities were according to the Radiation Oncology Group (RTOG) and the European Organization for Research and Treatment of Cancer (EORTC) Radiation Morbidity Schema [27]. Side effects were considered severe for grade $\geq 3$. Data on toxicity were collected from a local quality registry which includes information on all patients treated with radiotherapy for HNC in our clinic. In this registry, information on acute and late toxicities from skin, mucosa, larynx, salivary glands, dysphagia, mandible, and trismus is gathered and graded accordingly. These data are collected prospectively when patients come for routine follow-up visits every three months the first two years after treatment, and then every six months for another three years. For this study, toxicity data were supplemented with a review of medical records when needed. Toxicities presenting within 90 days of the last day of re-irradiation were considered acute. Toxicities presenting after this period were considered late toxicities. The specifically investigated toxicities were myelopathy, carotid blowout, ORN, trismus and dysphagia. Other grade $\geq 3$ late side effects (for example xerostomia and skin or mucosal ulcerations) were included in the total number of severe late side effects, but no associated OAR was considered. Carotid blowout syndrome was defined as a major bleeding from the pharynx in the absence of local recurrence.

\subsection{Organs at Risk}

The OARs investigated were the spinal cord, larynx, bones, mandible, and the carotid arteries. All OARs were delineated by a radiation oncologist specialized in HNC (AE). The spinal cord was delineated, as seen on the computed tomography (CT)-slices in level with the PTV with a minimum of $3 \mathrm{~cm}$ margin in cranio-caudal direction. The larynx was delineated to include the thyroid and cricoid cartilage. Bones were defined as all bony structures in the CT scan at re-irradiation. This structure was delineated using an auto-contouring tool and manually corrected in the high-dose region if needed (to exclude artefacts and non-bony structures incorrectly included). The mandible was delineated as it appears on the treatment planning images, excluding the teeth. Cranial limit was set at cranial limit of corpus mandibulae. In the carotid artery structure, the common, internal, and external carotid arteries were included bilaterally. The doses reported for the carotid arteries are the doses from the side that received the highest cumulative doses (i.e., only right or left).

The organs at risk were delineated on the CT-set from the reirradiation which was deformably registered to the CT-sets from the primary treatment for structure propagation and dose summation. Examples of the delineation of the OARs are shown in Figure 1. Dose/volume data for the spinal cord were investigated in relation to myelopathy, larynx in relation to dysphagia and laryngeal side effects (hoarseness, edema, chondritis and 
necrosis), bones/mandible in relation to ORN and carotid arteries in relation to carotid blowout syndrome.
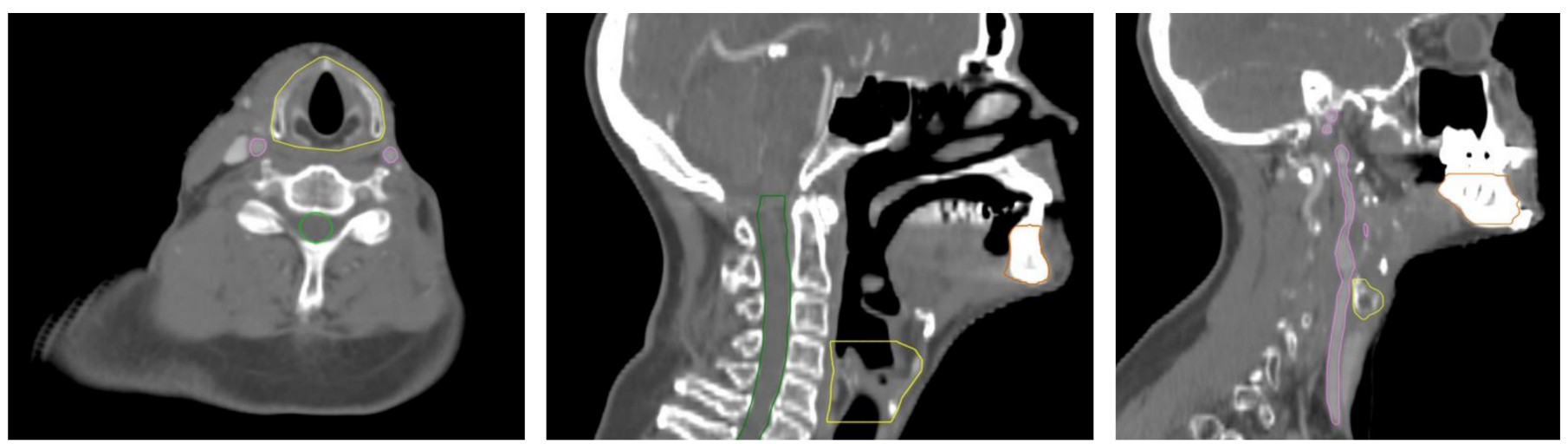

Figure 1. Delineation of organs at risk: larynx (yellow), spinal cord (green), mandible (brown), carotid artery (pink).

\subsection{Dose Accumulation}

The $3 \mathrm{D}$ dose distribution was collected from each course of treatment, including external beam radiotherapy and brachytherapy as described in our previous article [24]. For each patient, the different treatment planning images were registered to the most recent image set, which served as a reference image. A deformable registration was performed in Raystation using a mutual-information-based B-spline algorithm. The registration was visually validated for all patients, and a quantitative validation was performed for a subgroup of 14 patients. The latter consisted of manual delineation of three OARs (larynx, mandible, and carotids) in all treatment-planning images, for each patient, followed by a comparison of dose/volume statistics associated with the propagated OAR from deformable registration and the reference image structures, respectively.

The planned dose distribution from each course of treatment was converted to EQD2, using an in-house tool. This was followed by the dose accumulation from all courses of treatment on the reference CT series, facilitated by the deformable registration. Accumulated dose/volume statistics in EQD2 were then extracted for the OARs for each patient.

\subsection{Statistics}

The time to event approach using the Kaplan-Meier method was performed for each toxicity event separately. The adverse events were classified into acute or late events depending on time from re-radiation (within 90 days or more than that). In a subsequent step, a $t$-test and univariate logistic regression models were used to study potential associations between independent variables (tumor site, time between irradiations, re-irradiated volume (V100), PTV at re-irradiation) and toxicity. Receiver-operator characteristics (ROC) curves were used for the performance between dose/volume parameters and toxicity and to determine any cut-off values by using the Youden Index (J) to use as dose constraints. ROC analysis was performed for OAR with correlating events of severe toxicity to try and establish dose constraints (carotid arteries, bones, larynx). Statistical significance was considered at a 5\% alpha level and all the analysis was performed using $\mathrm{R}$ version 3.5.1.

\section{Results}

\subsection{Patient and Treatment Characteristics}

As described in our previous work [24], a total of 54 patients were included in the analysis and the overall survival at two and five years was 42.6 and $27.3 \%$, respectively, and progression free survival at two and five years was 32.5 and $28.5 \%$, respectively. The median follow-up time after re-irradiation was 54.1 months (range 34.3 to 66.3) 
in surviving patients and 20.1 months (range 0 to 69.9) in all included patients. The majority ( $94 \%$ ) of the included patients had a good performance status (ECOG 0-1) at the start of re-irradiation. Definitive re-irradiation (59\%) was more common compared to post-operative re-irradiation (41\%). The median re-irradiation dose was 59 Gy and the most common tumor site was the oropharynx (33\%) followed by cancer of the oral cavity $(31 \%)$.

\subsection{Toxicity}

The overall rate of any event of severe (grade $\geq 3$ ) acute and late toxicity was $26 \%$ and $51 \%$, respectively. There were two cases of fatal carotid blowout and these events occurred 15 and 38 months after re-irradiation. No cases of radiation-induced myelopathy were observed. Multiple $(>1)$ severe late side effects were seen in nine out of the $19(47 \%)$ patients that experienced serious late side effects. Seven patients died within 90 days of completing the reirradiation and are not eligible for analysis of late side effects. Most severe toxicity developed within 1.5 to 2 years after re-treatment, but ORN, dysphagia and carotid blowout appeared even after two to three years (Figure 2). The median time to develop any severe late side effect was 17 months. At closure of the database (20 December 2018) 11 out of 54 patients (20\%) were alive without disease, and at two years after re-irradiation, seven $(64 \%)$ of these patients had experienced no severe late side effects (Table 1).

Due to only one out of four events of ORN presenting in the mandible, no correlations between doses to the mandible and ORN were found and further dosimetric analysis considering ORN were on doses to bones.
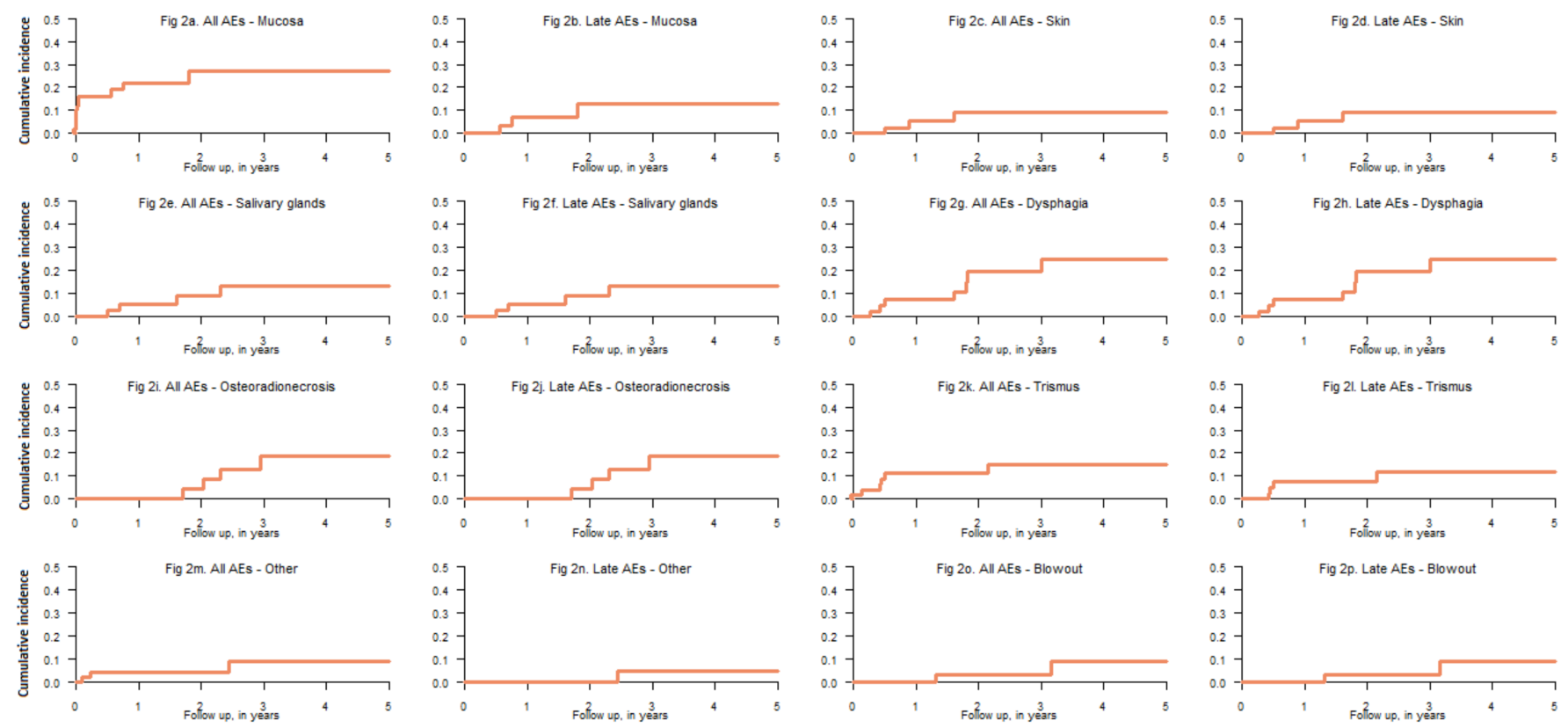

Figure 2. Time to event for all investigated severe side effects. Plots showing both time to any severe side effect and time to severe late side effect. $\mathrm{AE}$-adverse event, grade $\geq 3$ side effect. Others—one patient with grade 5 acute radiation-induced toxicity, one patient with neuropathy of the hypoglossal nerve, one patient with aspiration pneumonia. 
Table 1. Severe late side effects at two years in patients without disease at closure of database.

\begin{tabular}{cc}
\hline Subject & Late Side Effects Grade $\geq \mathbf{3}$ at Two Years After Re-Irradiation \\
\hline 10 & None \\
\hline 11 & Mucosa, Osteoradionecrosis \\
\hline 13 & None \\
\hline 19 & None \\
\hline 26 & None \\
\hline 27 & Skin, Mucosa, Xerostomia, Dysphagia \\
\hline 35 & None \\
\hline 37 & None \\
\hline 42 & Xerostomia \\
\hline 45 & None \\
\hline 52 & Osteoradionecrosis, Trismus \\
\hline
\end{tabular}

\subsection{Predictors of Toxicity}

We found no significant correlation between tumor site, time between irradiations, re-irradiated volume (V100), re-irradiation volume (PTV at re-irradiation) or severe side effects at first irradiation and the risk of developing any severe late side effects. The characteristics of all patients that experienced one or more grade $\geq 3$ late side effect are displayed in Table 2. The cumulative median near-maximum dose (D1cc) to the spinal cord, carotid arteries, larynx, and bones were $34 \mathrm{~Gy}$ (range 16 to $52 \mathrm{~Gy}$ ), $97 \mathrm{~Gy}$ (range 47 to $139 \mathrm{~Gy}$ ), $70 \mathrm{~Gy}$ (range 0 to $130 \mathrm{~Gy}$ ) and $118 \mathrm{~Gy}$ (range 69 to $141 \mathrm{~Gy}$ ), respectively. The cumulative median mean dose to the larynx was $46 \mathrm{~Gy}$ (range 0 to $79 \mathrm{~Gy}$ ). The doses to OARs for all patients are displayed in Figure 3a-d, highlighting patients with serious toxicity after re-treatment; the time between irradiations and the time to follow-up are indicated for each patient. Neither the time between irradiations nor the follow-up has any apparent influence on the outcome.

The composite dose volume histograms (DVH) show maximum doses to the carotid arteries to be near or above the upper third quartile for the two patients experiencing carotid blowout, implying higher cumulative maximum doses in these patients (Figure 4a). ROC-curve for a logistic model of carotid blowout vs. maximum doses to the carotid arteries showed AUC $=0.92$ (95\% CI 0.83 to 1.00) and a cut-off value of 119 Gy (sensitivity 1.00 /specificity 0.89 ) (Figure 5a). The near-maximum dose to bones showed a significant association with the risk of ORN: AUC $=0.74(95 \%$ CI 0.52 to 0.95$)$ and a cut-off value of 119 Gy (sensitivity 1.00/specificity 0.52) (Figure $5 b$ ); although with less separation between patients with and without toxicity compared to carotid blowout. This association can also be seen in the composite DVH for bones (Figure $4 \mathrm{~b}$ ). In contrast, the ROC analysis showed no significant association between the mean larynx dose and the risk of dysphagia (Figure 5c); this is similarly illustrated in Figures $3 c$ and $4 c$, where the patients with serious dysphagia did not generally receive higher dose to the larynx. 
Table 2. Table of characteristics of all patients with one or more grade $\geq 3$ late side effect(s).

\begin{tabular}{|c|c|c|c|c|c|c|c|c|c|c|c|c|c|c|c|c|c|c|c|}
\hline \multirow[b]{2}{*}{ Subject } & \multirow[b]{2}{*}{$\begin{array}{c}\text { Tumor Site at } \\
\text { First Presentation }\end{array}$} & \multicolumn{9}{|c|}{ Late Side Effects Grade $\geq 3$ after Re-RT } & \multirow[b]{2}{*}{$\begin{array}{l}\text { Surgery at First } \\
\text { Presentation }\end{array}$} & \multirow[b]{2}{*}{$\begin{array}{l}\text { Surgery Before } \\
\text { Re-RT }\end{array}$} & \multirow[b]{2}{*}{$\begin{array}{l}\text { PS at } \\
\text { Re-RT }\end{array}$} & \multirow[b]{2}{*}{$\begin{array}{l}\text { Grade } \geq 3 \text { side } \\
\text { effect at } 1 \text { st RT }\end{array}$} & \multirow{2}{*}{$\begin{array}{l}\text { Time between RT } \\
\text { and re-RT } \\
\text { (months) }\end{array}$} & \multirow{2}{*}{$\begin{array}{l}\text { Age at } \\
\text { Re-RT } \\
\text { (years) }\end{array}$} & \multirow{2}{*}{$\begin{array}{l}\text { PTV at } \\
\text { Re-RT } \\
\left(\mathrm{cm}^{3}\right)\end{array}$} & \multirow{2}{*}{$\begin{array}{l}\text { V100 at } \\
\text { Re-RT } \\
\left(\mathrm{cm}^{3}\right)\end{array}$} & \multirow{2}{*}{$\begin{array}{l}\text { Concomitant } \\
\text { Systemic Therapy } \\
\text { at Re-RT }\end{array}$} \\
\hline & & Skin & Mucosa & Larynx & $\begin{array}{c}\text { Salivary } \\
\text { Glands }\end{array}$ & Dysphagia & ORN & Trismus & Blowout & Other & & & & & & & & & \\
\hline 52 & Sino/nasal & No & No & No & No & No & Grade 4 & Grade 3 & No & No & Primary tumor & No & 0 & No & 88 & 41 & 62 & 71 & No \\
\hline 42 & Nasopharyngeal & No & No & No & Grade 3 & No & No & No & No & Grade 3 & No & No & 0 & No & 60 & 55 & 248 & 91 & No \\
\hline 27 & Oral cavity & Grade 3 & Grade 3 & No & Grade 3 & Grade 3 & No & No & No & No & Primary tumor & Primary tumor & 0 & No & 108 & 62 & 198 & 256 & No \\
\hline 30 & Oral cavity & No & No & No & No & No & No & Grade 3 & No & No & No & No & 1 & No & 78 & 60 & 161 & 167 & No \\
\hline 41 & Oral cavity & No & No & No & No & Grade 3 & No & No & No & No & Primary tumor $+\mathrm{ND}$ & No & 0 & Yes & 127 & 60 & 44 & 82 & No \\
\hline 7 & Oropharyngeal $^{\dagger}$ & No & Grade 3 & No & Grade 3 & Grade 3 & No & No & No & No & No & Primary tumor & 0 & No & 138 & 74 & 309 & 87 & No \\
\hline 22 & Oropharyngeal ${ }^{*}$ & No & No & No & No & Grade 4 & No & Grade 4 & No & No & No & No & 0 & No & 36 & 68 & 128 & 142 & No \\
\hline 31 & Oropharyngeal ${ }^{*}$ & Grade 3 & No & No & Grade 3 & Grade 3 & No & Grade 3 & No & No & No & Primary tumor & 0 & No & 50 & 61 & 333 & 120 & No \\
\hline 37 & Oropharyngeal ${ }^{*}$ & No & No & No & No & No & Grade 4 & No & No & No & No & Primary tumor & 0 & No & 136 & 59 & 219 & 154 & No \\
\hline 38 & Oropharyngeal ${ }^{*}$ & No & No & No & No & No & Grade 3 & No & Grade 5 & No & No & Primary tumor & 1 & No & 31 & 56 & 106 & 138 & No \\
\hline 6 & Hypopharyngeal & No & Grade 4 & No & No & No & No & No & No & No & No & No & 0 & No & 43 & 74 & 93 & 64 & No \\
\hline 20 & Hypopharyngeal & No & Grade 3 & No & No & No & No & No & No & No & No & No & 0 & Yes & 21 & 64 & 149 & 109 & No \\
\hline 24 & Hypopharyngeal & No & No & No & No & Grade 3 & No & No & No & No & No & Primary tumor $+\mathrm{ND}$ & 0 & No & 71 & 64 & 26 & 56 & No \\
\hline 9 & Larynx & No & No & No & No & No & No & No & Grade 5 & No & Primary tumor $+\mathrm{ND}$ & ND & 1 & No & 15 & 74 & 66 & 92 & No \\
\hline 19 & Larynx & No & No & No & No & Grade 4 & No & No & No & No & No & Primary tumor + ND & 0 & No & 15 & 68 & 452 & 76 & No \\
\hline $\begin{array}{l}\text { Median (whole } \\
\text { cohort) }\end{array}$ & & & & & & & & & & & & & $\begin{array}{l}95 \% \text { was } \\
\text { PS } 0-1\end{array}$ & & 36 & 63 & 145 & 90 & \\
\hline
\end{tabular}

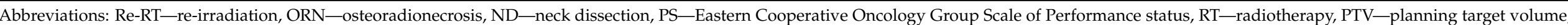
V100—volume with a cumulative dose of $\geq 100 \mathrm{~Gy}$, HPV—human papilloma virus. ${ }^{*} \mathrm{HPV}$ positive, ${ }^{\dagger} \mathrm{HPV}$ status unknown. 


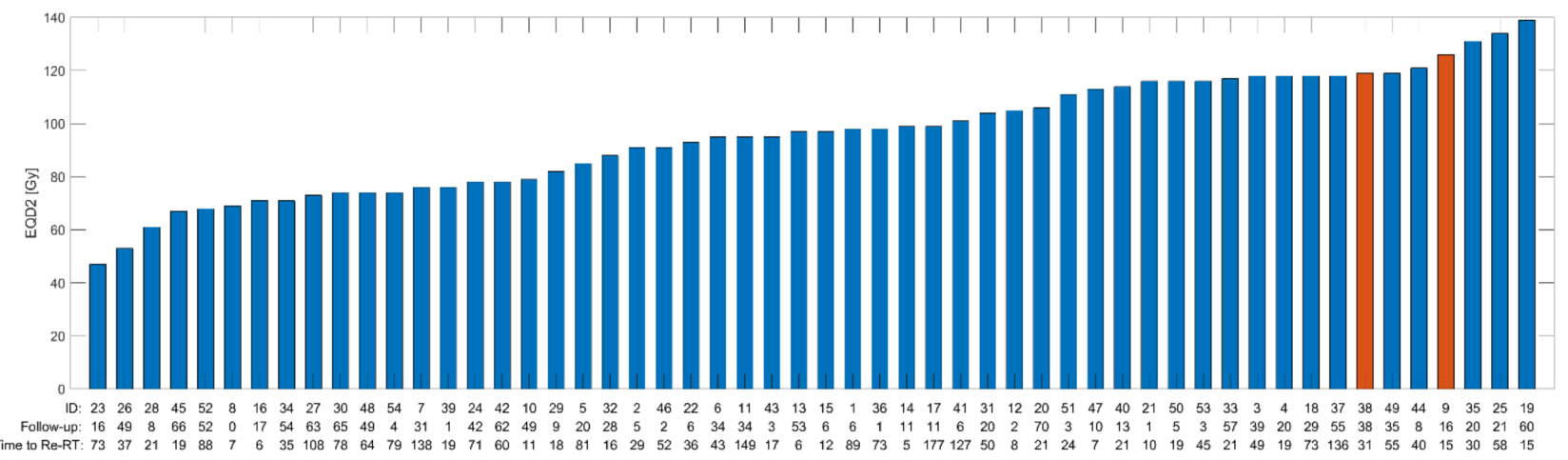

(a)

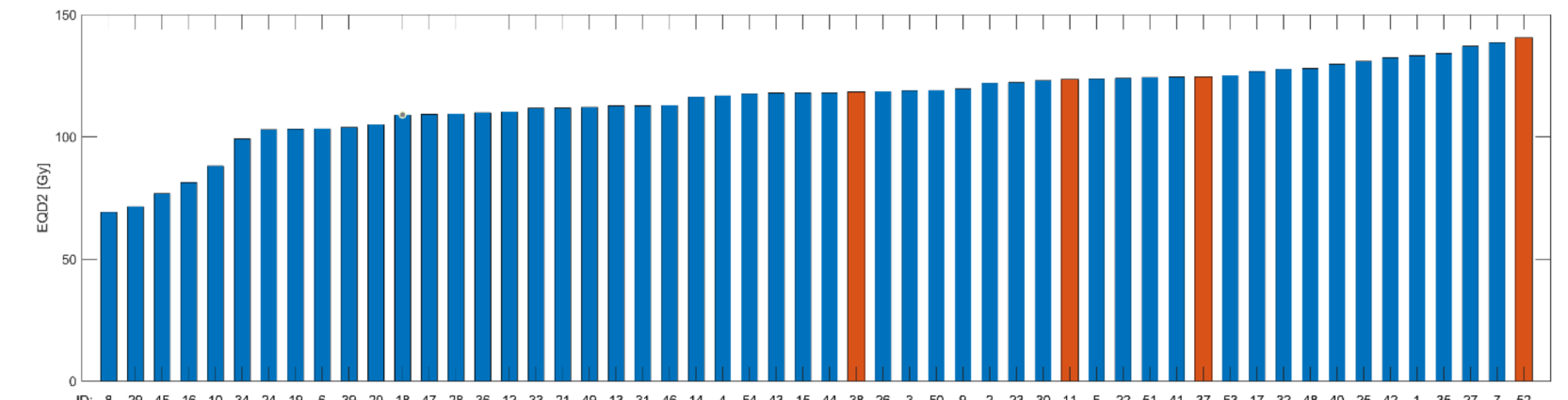

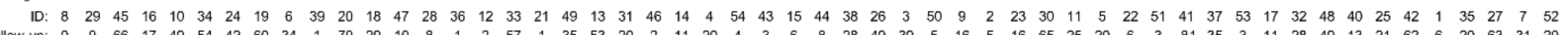

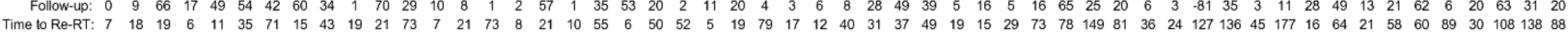

(b)

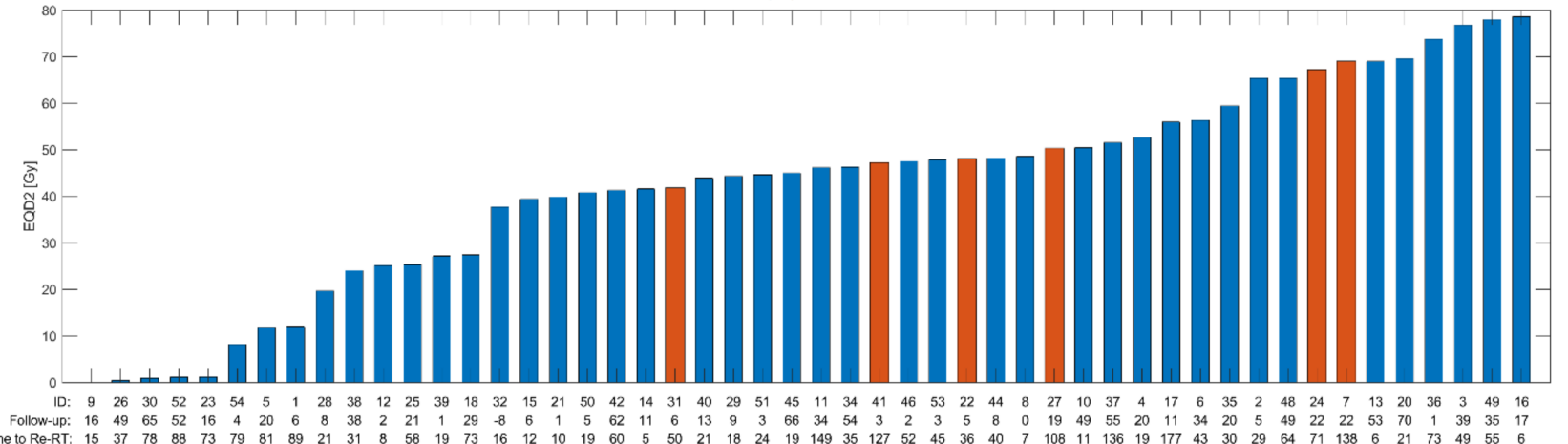

(c)

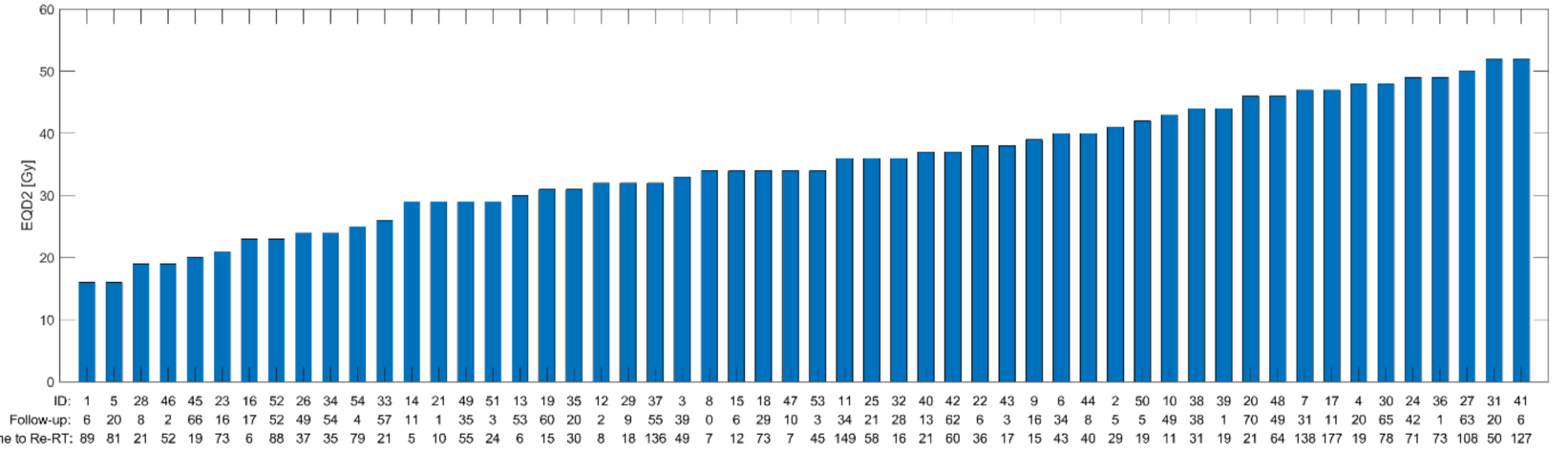

(d)

Figure 3. Histograms of cumulative dose in EQD2 in all included patients. Red bars indicating patient with severe side effect. The time between irradiations and the time to follow-up are indicated for each patient. (a) Maximum dose (D1cc) to carotid artery and carotid blowout syndrome. (b) Maximum dose (D1cc) to bones and grade $\geq 3$ osteoradionecrosis. (c) Mean dose to larynx and grade $\geq 3$ dysphagia. (d) Maximum dose (D1cc) to spinal cord and no events of neuropathy. Abbreviations: ID—identification number of subject, Re-RT—re-irradiation. 


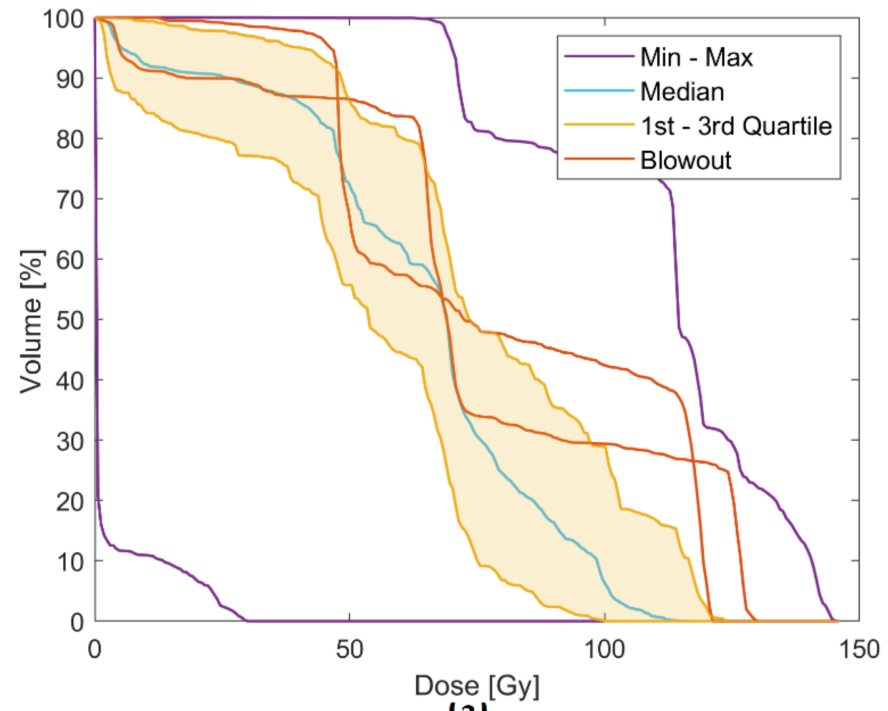

(a)

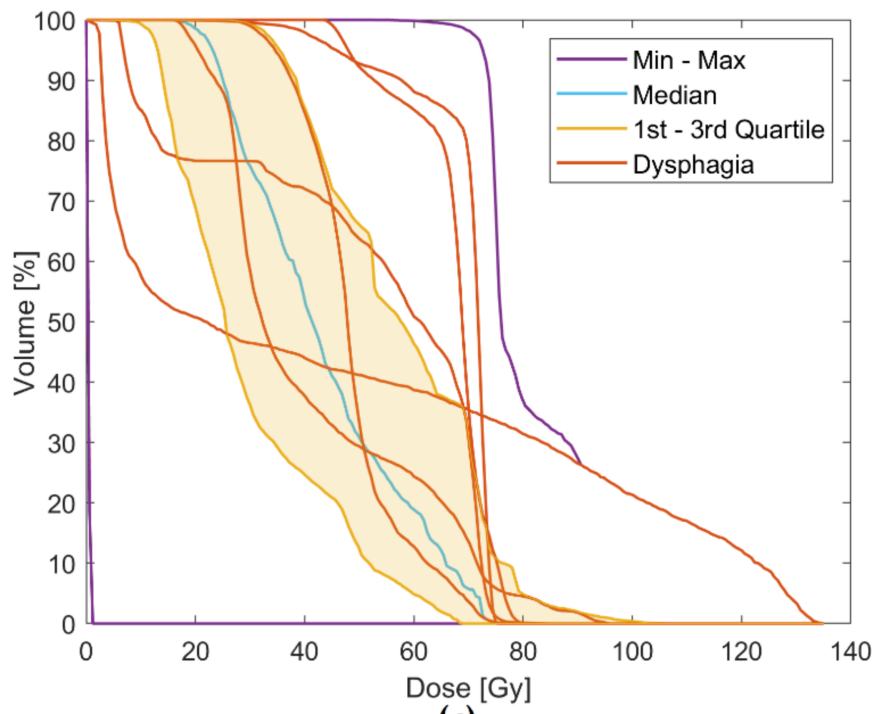

(c)

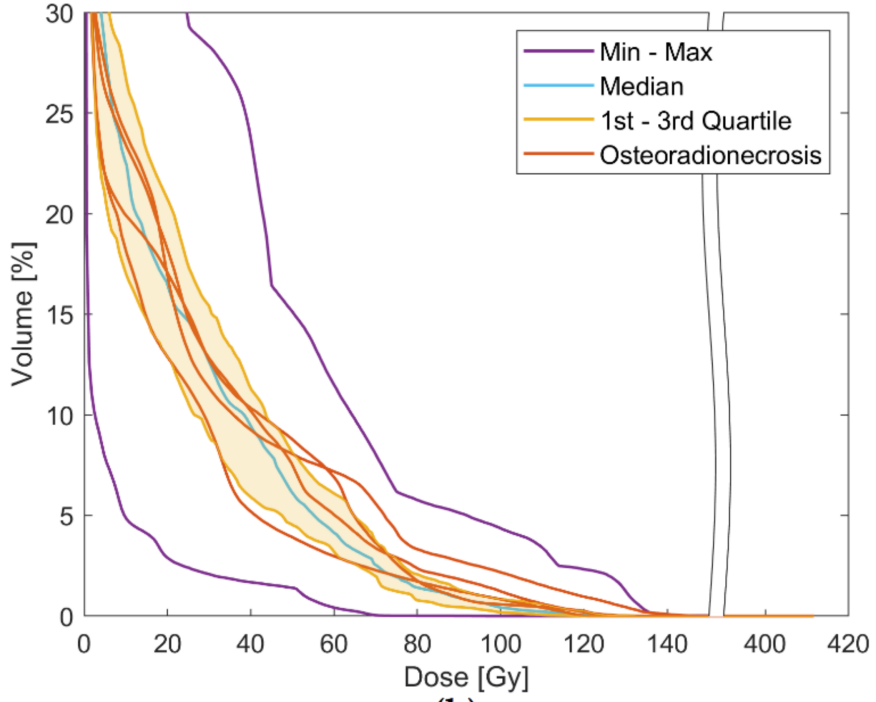

(b)

Figure 4. Composite dose volume histograms (DVH) highlighting the individual DVHs of patients with severe side effects. (a) Dose in EQD2 to carotid artery and blowout syndrome. (b) Dose in EQD2 to bones and grade $\geq 3$ osteoradionecrosis. (c) Dose in EQD2 to larynx and grade $\geq 3$ dysphagia. 


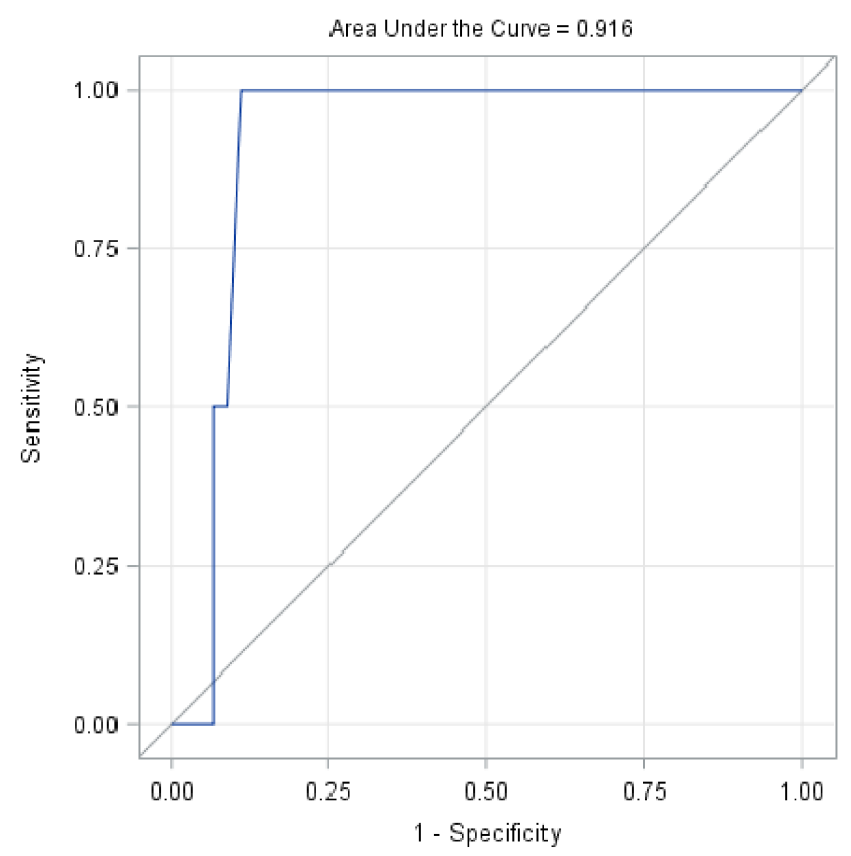

(a)

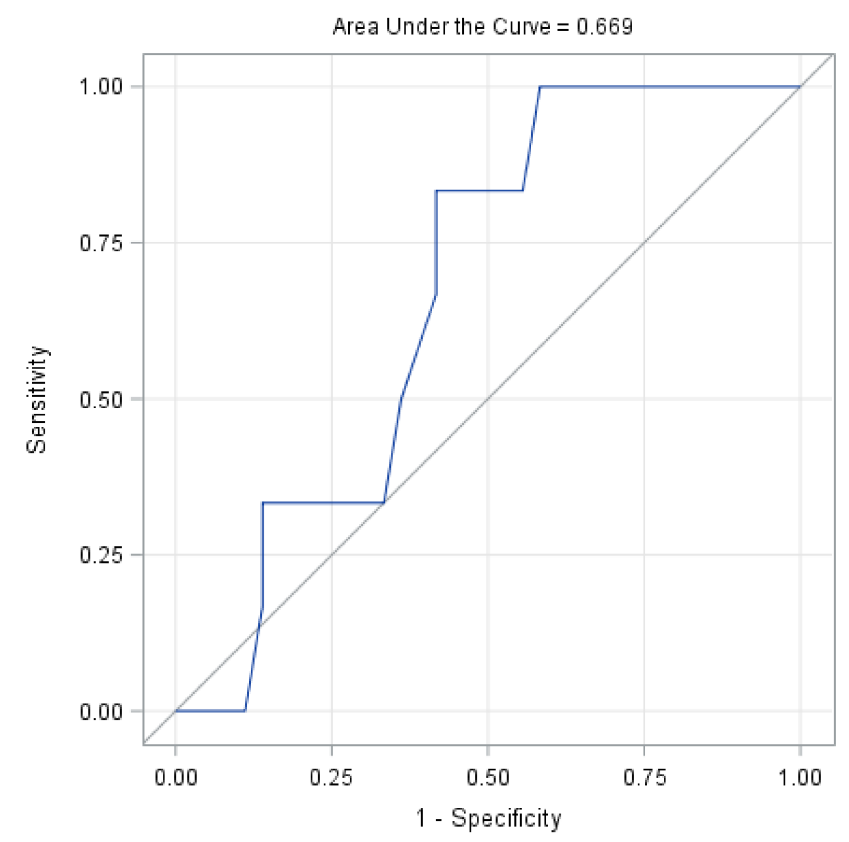

(c)

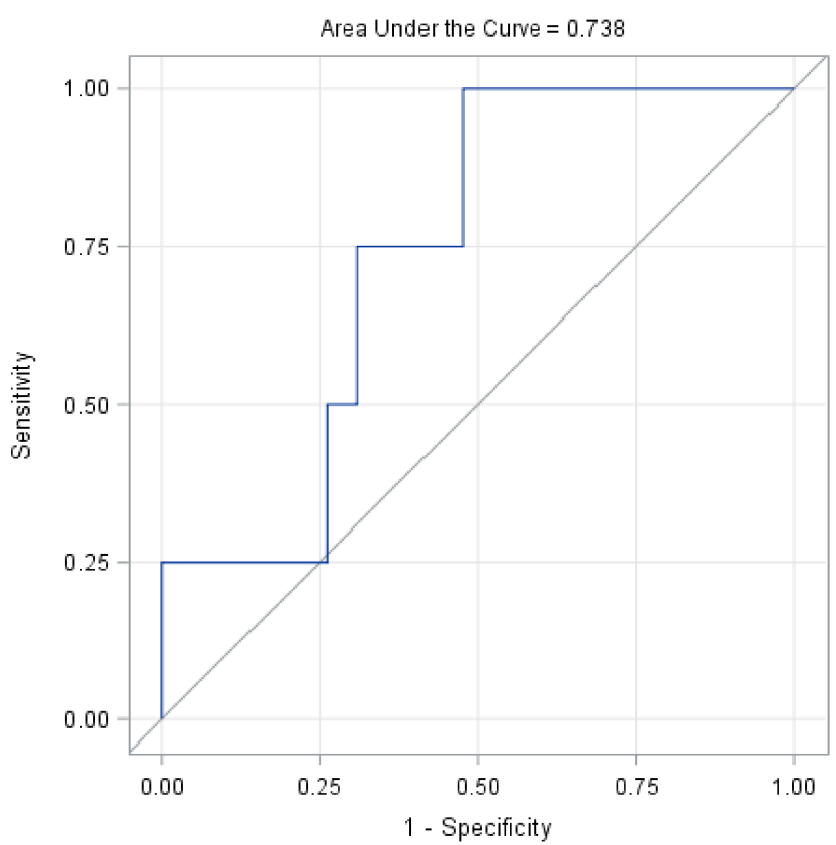

(b)

Figure 5. Receiver-operator characteristics (ROC) curve for logistic model. (a) Maximum dose (D1cc) to carotid artery and carotid blowout syndrome. AUC 0.92 (95\% CI 0.83 to 1.00) and a cut-off value of 119 Gy (sensitivity 1.00/specificity 0.89 ). (b) Maximum dose (D1cc) to bones and grade $\geq 3$ osteoradionecrosis. AUC $=0.74$ (95\% CI 0.52 to 0.95$)$ and a cut-off value of 119 Gy (sensitivity 1.00/specificity 0.52). (c) Mean dose to larynx and grade $\geq 3$ dysphagia. AUC $=0.67$ (95\% CI 0.49 to 0.85 ).

\section{Discussion}

This is one of the larger studies on re-irradiation for HNC that presents extensive dose/volume data, cumulative doses to OARs and side effects for all included patients. Our strict definition of re-irradiation may have contributed to the seemingly high rates of late side effects. Previously published studies with a vaguer definition of re-irradiation may have included patients with an overlap only in low dose volumes, resulting in an 
underestimation of the incidence of side effects after re-irradiation. Another factor that may have contributed to the seemingly high rates of late side effects is the relatively long time to last follow-up of 54 months in surviving patients. We specifically explored the side effects carotid blowout syndrome, dysphagia, ORN and trismus, but all grade $\geq 3$ side effects were recorded, thus considering the most common side effects after re-irradiation [20].

The cut-off value of 119 Gy (EQD2) for the maximum dose to the carotid arteries was very similar to the cut-off value of 120 Gy suggested by Garg et al. [18] (Table 3). This is a valuable validation of these results, although this is a dose constraint that will not always be possible to follow, as the carotid arteries are quite often in close proximity of both the prior high dose volume and the planned re-irradiation volume. As standard primary treatment is often 68 to $70 \mathrm{~Gy}[28,29]$ and the recommended re-irradiation dose is 60 to $68 \mathrm{~Gy}[30,31]$, an overlap of these two volumes close to the carotid artery will result in a cumulative dose well over 119 to $120 \mathrm{~Gy}$, so to stand a chance of eradicating the tumor, the dose constraint will have to be exceeded. However, the knowledge of an increased risk of carotid blowout syndrome, if exceeding the dose limit, is valuable in the discussion with the patient on deciding what treatment option to choose and in the discussion on risk-benefit balancing in re-irradiation.

Table 3. Table of dose/volume predictors of toxicity after re-irradiation.

\begin{tabular}{ccc}
\hline \multirow{2}{*}{ Author, Year, Reference Number } & \multicolumn{2}{c}{ Cumulative Maximum Dose * } \\
\cline { 2 - 3 } & Carotid Blowout & Osteoradionecrosis \\
\hline Embring et al., 2021(current article) & $119 \mathrm{~Gy}$ & $119 \mathrm{~Gy}$ \\
Garg et al., 2016 [18] & $120 \mathrm{~Gy}$ & - \\
Bots et al., 2017 [17] & - & $114 \mathrm{~Gy}$ \\
\hline${ }^{*}$ maximum dose or near-maximum dose. & &
\end{tabular}

In the previously mentioned study by Bots et al., patients that developed ORN after re-irradiation had received a median cumulative dose of $114 \mathrm{~Gy}$ (physical dose to site of complication) [17] (Table 3). This is not far from the cut-off value of 119 Gy to bones we found in our material. This value should be more reliable compared to Bots' study, where cumulative dose distributions were not produced, but an estimation of the maximum summed radiation point dose in the OARs was made. This was due to the lack of volume data from patients treated in earlier years and it was therefore not possible to analyze dose/volume relationships, a weakness pointed out by the authors themselves. Furthermore, Bots stated that there were no cases of mandibular ORN in the group of patients with a cumulative dose of $<100 \mathrm{~Gy}$, which corresponds well with our results of no cases of ORN in the group of patients with a cumulative dose of $<100$ Gy to bones.

In contrast to previously published data, we found no significant correlation between the time between irradiations or re-irradiation volume (PTV at re-irradiation) and the risk of developing any severe late side effects. In the study by Lee at el., shorter time ( $<20$ months) between irradiations and a PTV $>100 \mathrm{~cm}^{3}$ were both independent predictors of developing severe late side effects [19]. Additionally, Phan et al. have shown that a larger treatment volume at re-irradiation (clinical target volume $>50 \mathrm{~cm}^{3}$ ) was correlated to both acute and severe late side effects [32]. The reason these correlations were not demonstrated in our study could be our relatively small cohort.

In our study, the most severe late toxicity developed within 1.5 to 2 years after retreatment and the median time to develop any severe late side effect was 17 months. This is consistent with the findings in the study by Ward et al. [13]. In that large multi-institutional study including 505 patients, severe late side effects presented at a median of 9.2 months and the majority of all late side effects presented within two years (74 of 85 events). Multiple severe late side effects were seen in $21 \%$ of the patients compared to $47 \%$ in our study. A contributing factor to the Ward study showing a median time to event shorter than ours and considerably less multiple severe late side effects could be our longer follow-up time 
(54.1 months compared to Ward's 21.5 months, in surviving patients) and therefore the recording of more events occurring later.

It is difficult to value the incidence of side effects after re-irradiation and what rates could be considered acceptable in the cost-benefit balance between toxicity and tumor control. To explore this further, we compared the incidence of dysphagia and trismus in this re-irradiation cohort with the incidence of the same side effects in a reference cohort of more than 700 patients treated with primary radiotherapy with curative intent. A detailed description of this evaluation is given in Appendix B.

This comparison showed that the cumulative incidence of dysphagia (grade $\geq 3$ ) in an identified subgroup (high laryngeal dose) of $17 \%$ of the patients in the reference cohort had about the same cumulative incidence of dysphagia as the patients that have received re-irradiation (24\% at three years) (see Appendix B, Figure A1a,b). This could imply that the incidence of dysphagia in the re-irradiation cohort is not excessive.

The incidence of trismus (grade $\geq 3$ ) was much higher in the re-irradiated cohort compared to the reference cohort (see Appendix B, Figure A1c,d). This could be due to the extensive treatment many of the patients with recurrent $\mathrm{HNC}$ have experienced compared to patients treated for primary HNC only. However, the cumulative incidence of trismus in the re-irradiation cohort was still reasonably low (12\% at three years) and could be considered acceptable due to the clinical situation.

Patient-related factors, such as smoking status and comorbidity, have been shown to have an impact on the development of side effects after radiotherapy in general and re-irradiation in particular [14,33], and as previously mentioned, the growth pattern of the tumor in relation to the carotid arteries may play a role in the risk of developing carotid blowout syndrome [23]. A weakness of our study is that these patients and tumor-related factors were not available, likely confounding our results to some degree.

When considering re-irradiation for HNC patients in our clinic, we follow our local guidelines for patient selection and treatment, based on the current literature. Our only strict dose constraint is for the cumulative dose to the spinal cord (and where relevant, also the brainstem), which is more highly prioritized than covering the target volume with the prescribed dose. For the spinal cord, we assume some normal tissue repair between the irradiations, as suggested by Nieder et al. [22]. A dose constraint of lower priority is the cumulative dose to the carotid arteries, where we avoid doses $>120$ Gy when possible, but covering the target volume is of a higher priority, which sometimes results in exceeding this constraint. Doses to other OARs and overlapping re-irradiation volumes are evaluated individually for each patient.

As Garg [18] and Bots [17] have stated before us, cumulative dose/volume data are essential to improve re-irradiation strategies. Radiotherapy requires a fine balance between sufficiently high doses to the tumor, while maintaining doses to OARs at an acceptable level. At re-irradiation, higher rates of severe side effects are expected compared to after primary treatment, due to the higher cumulative doses. This can to some extent be considered acceptable, because of the limited treatment options available for patients with recurrent or second primary HNC. Re-irradiation can offer long-term local control and sometimes even cure, but this might come with a high level of severe side effects. However, the current study shows that not all patients re-irradiated for HNC suffer from severe late side effects. In the 11 patients without disease at closure of our data base, the majority $(64 \%)$ had experienced no severe late side effects two years after re-irradiation. Greater knowledge regarding normal tissue tolerance at re-irradiation will facilitate improved treatment plans and might improve the risk-benefit ratio. Alternatives in immunotherapy are also emerging. Immunotherapy alone will only help a small proportion of patients with recurrent $\mathrm{HNC}$, but a combination of different modalities, such as re-irradiation and immunotherapy, will possibly result in better outcomes. There are currently several trials registered on clinicaltrials.gov investigating this combination. Further studies on re-irradiation for HNC are needed to explore dose/volume data and new combinations of modalities, and preferably, these studies would also include quality of life data. 


\section{Conclusions}

Careful accumulation of dose to OARs demonstrated an association between cumulative dose and the risk of developing ORN and carotid blowout, and the results support the existing dose constraint for the carotid arteries of $120 \mathrm{~Gy}$. Re-irradiation should be considered as a treatment option for patients with recurrent HNC as it has been shown to offer long-lasting tumor control and even cure for selected patients and this material shows that a group of patients will have long-lasting tumor control without experiencing severe late side effects. With careful consideration of cumulative dose/volume data, treatment plans can be tailored to optimize the risk-benefit ratio for the individual patient.

Author Contributions: Conceptualization, A.E., E.O., C.M., I.L., A.B., and S.F.; methodology, A.E., E.O., C.M., I.L., A.B., and S.F.; software, S.B., B.W., and E.D.; validation, A.E., E.O., C.M., I.L., A.B., and S.F.; formal analysis, A.B.; investigation, A.E., E.O., S.B., B.W., and E.D.; resources, I.L. and S.F.; data curation, A.E.; writing-original draft preparation, A.E.; writing-review and editing, E.O., C.M., I.L., A.B., and S.F.; visualization, A.E.; supervision, E.O., C.M., I.L., and S.F.; project administration, A.E.; funding acquisition, I.L. and S.F. All authors have read and agreed to the published version of the manuscript.

Funding: This study was partly funded by a grant (number 164082) from the King Gustaf V Jubilee Fund (Stockholm, Sweden).

Institutional Review Board Statement: The study was conducted according to the guidelines of the Declaration of Helsinki and approved by the Swedish National Ethical Review Authority. Number of ethics approval: 2017/2498-31.

Informed Consent Statement: Patient consent was waived due to the ethical approval stating that no consent to participate was required for this study.

Data Availability Statement: Research data are stored in an institutional repository and will be shared upon reasonable request to the corresponding author.

Conflicts of Interest: The authors declare no conflict of interest.

\section{Appendix A}

Table A1. Patient and Treatment Characteristics at First Presentation.

\begin{tabular}{ccc}
\hline $\begin{array}{c}\text { Patient and Treatment } \\
\text { Characteristics at First Presentation }\end{array}$ & Number & Percent (Range) \\
\hline Male & 35 & 65 \\
Female & 19 & 35 \\
Median age (years) & 59 & $(33$ to 81$)$ \\
Tumor site & & \\
\hline Larynx & 6 & 11 \\
Oropharyngeal * & 18 & 33 \\
Nasopharyngeal & 1 & 2 \\
Hypopharyngeal & 5 & 9 \\
Oral cavity & 17 & 31 \\
Unknown primary & 2 & 4 \\
Sino/nasal & 3 & 6 \\
Salivary gland & 2 & 4 \\
Histology & & 85 \\
Squamous cell carcinoma & 46 & 9 \\
Adenoid cystic carcinoma & 5 & 6 \\
Other ${ }^{\dagger}$ & 3 & \\
Tumor Stage & & \\
\hline
\end{tabular}


Table A1. Cont.

\begin{tabular}{ccc}
\hline $\begin{array}{c}\text { Patient and Treatment } \\
\text { Characteristics at First Presentation }\end{array}$ & Number & Percent (Range) \\
\hline I & 5 & 9 \\
II & 11 & 20 \\
III & 7 & 13 \\
IVa & 28 & 52 \\
IVb & 3 & 6 \\
T-stage & 2 & 4 \\
0 & 9 & 17 \\
1 & 22 & 41 \\
2 & 4 & 7 \\
3 & 17 & 31 \\
4 & 68 & $(60-79)$ \\
\hline Median treatment dose (Gy) & & \\
Tumor stage according to American Joint Committee on Cancer (AJCC) Cancer Staging Manual 7 th edition. \\
* Association with human papilloma virus (HPV): 11 HPV-positive, two HPV-negative, five HPV status unknown. \\
tone salivary duct cancer, one undifferentiated non-keratinizing cancer, one adenocarcinoma. Bold font is used \\
to mark subheadings.
\end{tabular}

Table A2. Patient and Treatment Characteristics at Re-irradiation.

\begin{tabular}{|c|c|c|}
\hline $\begin{array}{l}\text { Patient and Treatment Characteristics } \\
\text { at Re-Irradiation }\end{array}$ & Number & Percent (Range) \\
\hline Median age at end of re-irradiation (years) & 63 & (40 to 89$)$ \\
\hline Median time between radiations (months) & 36 & (5 to 177$)$ \\
\hline \multicolumn{3}{|l|}{ Performance status } \\
\hline $\begin{array}{c}0 \\
1 \\
2 \\
3 \\
\text { Tumor } \\
\end{array}$ & $\begin{array}{c}30 \\
21 \\
2 \\
1\end{array}$ & $\begin{array}{c}56 \\
39 \\
4 \\
2\end{array}$ \\
\hline $\begin{array}{c}\text { Local recurrence } \\
\text { Secondary primary tumor } \\
\text { Surgery before re-irradiation }\end{array}$ & $\begin{array}{l}37 \\
17\end{array}$ & $\begin{array}{l}69 \\
31\end{array}$ \\
\hline $\begin{array}{c}\text { No } \\
\text { Primary tumor } \\
\text { Neck dissection } \\
\text { Primary tumor and neck dissection } \\
\text { Systemic medical treatment }\end{array}$ & $\begin{array}{c}32 \\
11 \\
8 \\
3\end{array}$ & $\begin{array}{c}59 \\
20 \\
15 \\
6\end{array}$ \\
\hline $\begin{array}{c}\text { No } \\
\text { Induction chemotherapy } \\
\text { Concurrent chemotherapy (cisplatin) } \\
\text { Concurrent cetuximab } \\
\text { Radiotherapy technique at re-irradiation }\end{array}$ & $\begin{array}{c}41 \\
11 \\
1 \\
1\end{array}$ & $\begin{array}{c}76 \\
20 \\
2 \\
2\end{array}$ \\
\hline $\begin{array}{c}\text { VMAT/IMRT } \\
\text { VMAT/IMRT + brachytherapy } \\
3 \text { D conformal } \\
3 \text { D conformal + brachytherapy } \\
\text { Brachytherapy }\end{array}$ & $\begin{array}{l}45 \\
3 \\
4 \\
1 \\
1\end{array}$ & $\begin{array}{c}83 \\
6 \\
7 \\
2 \\
2\end{array}$ \\
\hline Median re-irradiation dose (Gy) & 59 & $(40$ to 71$)$ \\
\hline Median cumulative near max dose, D1cc (Gy) & 129 & $(106$ to 478$)$ \\
\hline Median PTV at re-irradiation $\left(\mathrm{cm}^{3}\right)$ & 145 & $(13$ to 668$)$ \\
\hline Median re-treated volume, V100 $\left(\mathrm{cm}^{3}\right)$ & 90 & (2 to 283 ) \\
\hline
\end{tabular}

Abbreviations: VMAT—volumetric modulated arc therapy, IMRT—intensity-modulated radiotherapy, PTVplanning target volume. Bold font is used to mark subheadings. 


\section{Appendix B}

\section{Appendix B.1. Reference Cohort}

To assess whether the incidence of severe side effects is excessive compared to the single-treatment setting, a reference cohort was used for comparison. The reference cohort (more than 700 patients) was extracted from a local quality registry and consisted for patients that have received primary radiotherapy with curative intention. It was possible to identify subgroups with high rates of late dysphagia (grade $\geq 3$ ) and late trismus (grade $\geq 3$ ) from registry data of patients with oral cavity and oropharyngeal cancer. The subgroups have been identified from a significant statistical relationship between the mean dose to the larynx and the incidence of late dysphagia as well as a statistical relationship between the mean dose to the parotid glands and the incidence of late trismus (unpublished data). The subgroups were selected from percentiles of mean larynx- and parotid doses, respectively.

The incidence of dysphagia and trismus in these subgroups were compared with the incidence of dysphagia and trismus in the re-irradiation cohort. The OARs examined (larynx and parotid glands) and the subsequent toxicity studied were chosen as a statistical relationship was found. Both these OARs are in close anatomical proximity to structures that can be supposed to be affected by high absorbed dose and involved in the cause of the subsequent toxicity analyzed. Therefore, it also seems reasonable to use these structures as surrogate OARs, correlating to these side effects not only due to the statistical relationship.

\section{Appendix B.2. Comparison of morbidity to the Reference Cohort}

Figure A1a,b and Figure A1c,d show the cumulative incidence of, respectively, all/late dysphagia, grade $\geq 3$ and all/late trismus, grade $\geq 3$, for some of the subgroups, the complete reference cohort as well as for the re-irradiation cohort. The reference cohort for dysphagia consisted of 739 patients and the 90\% (EQD2 $\geq 44 \mathrm{~Gy}$ ) and 80\% (EQD2 $\geq 40 \mathrm{~Gy}$ ) larynx dose percentiles consisted of, respectively, $8 \%$ and $17 \%$ of that cohort. The reference cohort for trismus consisted of 702 patients and the $90 \%$ (EQD2 $\geq 28 \mathrm{~Gy}$ ) and $80 \%$ (EQD2 $\geq 26 \mathrm{~Gy}$ ) parotid dose percentiles consisted of, respectively, $11 \%$ and $20 \%$ of that cohort.

The cumulative incidence of dysphagia (grade $\geq 3$ ) in the re-irradiated cohort was $24 \%$ at three years, which was quite similar to the cumulative incidence of dysphagia in a subgroup $(80 \%$ percentile) of $17 \%$ of the patients in the reference cohort receiving the highest doses to the larynx (Figure A1a,b). In another subgroup ( $90 \%$ percentile) consisting of $8 \%$ of the reference cohort, the cumulative incidence was $33 \%$ at three years. This indicates that the incidence of dysphagia in the re-irradiation cohort is not excessive, considering the results of local control in the re-irradiated cohort [24]. The pattern of time to event, as seen in Figure A1a,b, is similar in the re-irradiation cohort and the reference cohort.

The cumulative incidence of late trismus (grade $\geq 3$ ) was $8 \%$ at six months and $12 \%$ at three years in the re-irradiated cohort. This was higher compared to the reference cohort including all identified sub-groups. Although the incidence of trismus (grade $\geq 3$ ) is not very high in the re-irradiated cohort, it is considerably higher compared to the complete reference cohort and also to the sub-groups with higher incidence (Figure A1c,d). This is not surprising as patients with recurrent $\mathrm{HNC}$ have often undergone multiple treatments that can affect the ability to open the mouth, such as radiotherapy, surgery, and chemotherapy. Re-irradiation has been shown to be a risk factor for developing trismus in a study by van der Geer et al. [34]. Examples of other factors also associated with trismus in the same study were: chemotherapy, advanced age, a free soft tissue transfer and tumors located at the maxilla, mandible, major salivary gland, cheek, oropharynx or a tumor of unknown primary. When studying the pattern of time to event in the current study (Figure A1c,d), trismus seems to develop earlier in the re-irradiated patients compared to the reference cohort. The reason for this is unclear, but it is possible that prior treatment(s) will contribute to an earlier development of trismus. 


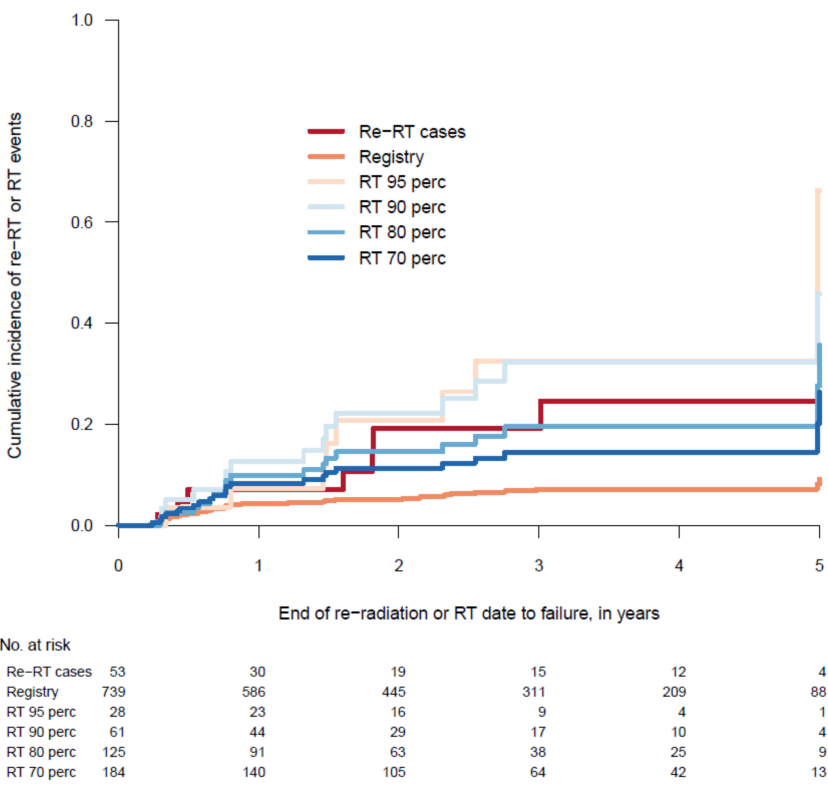

(a)

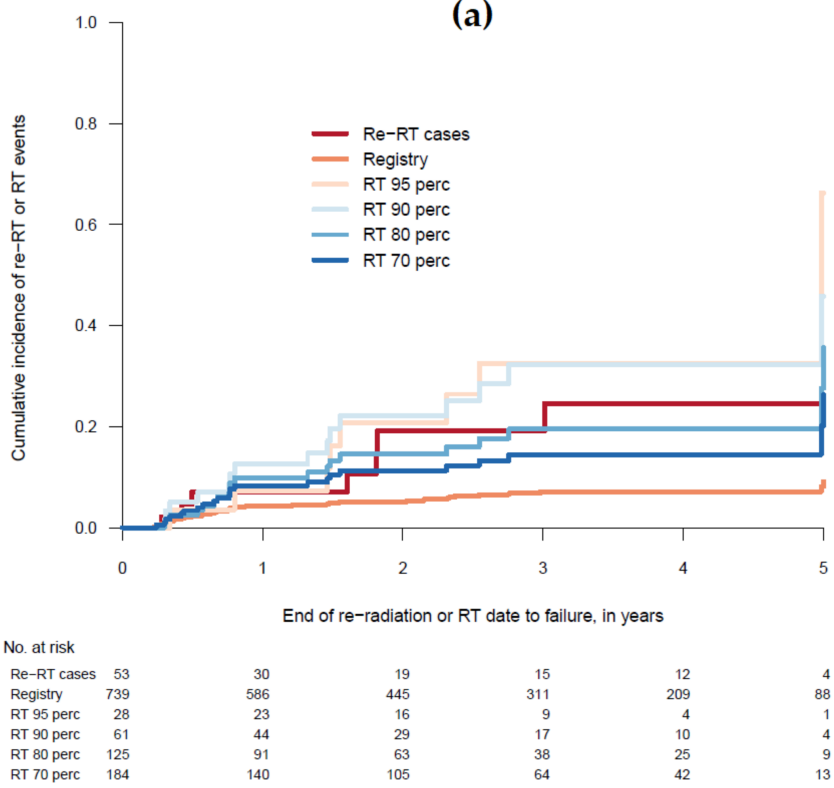

(c)

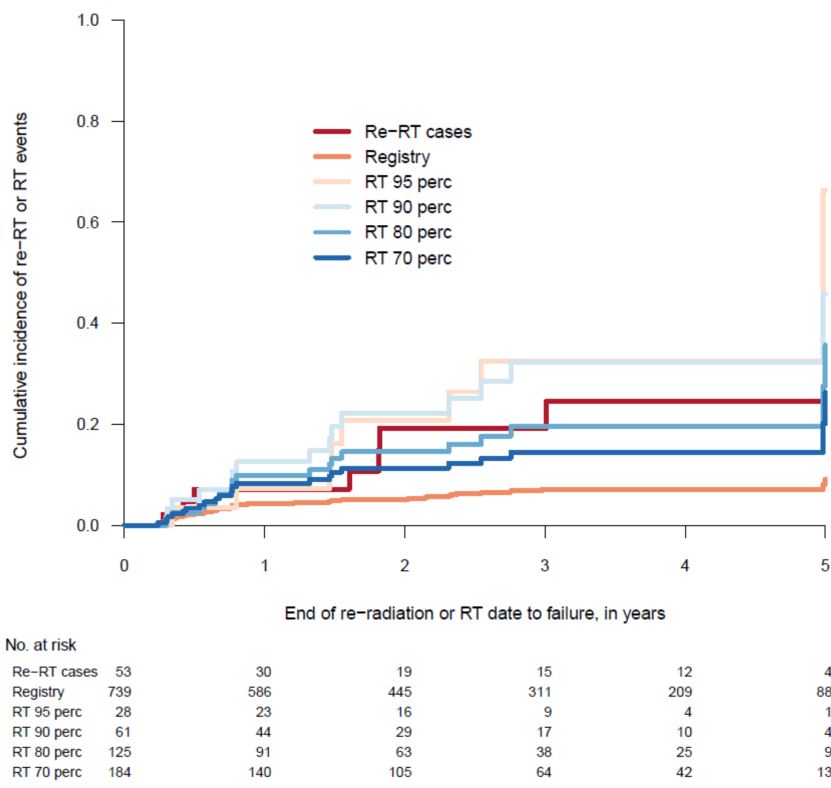

(b)

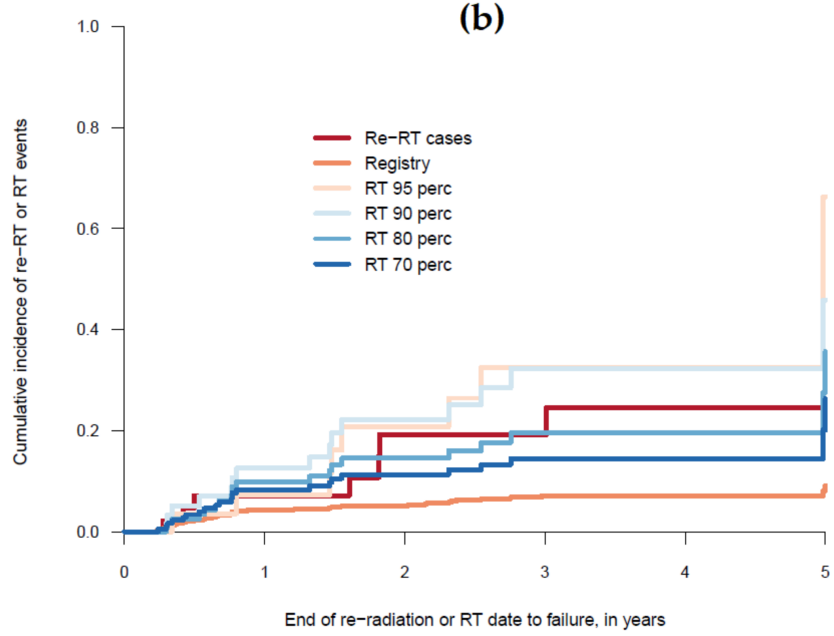

No. at risk

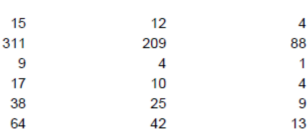

(d)

Figure A1. Time to grade $\geq 3$ side effect. Re-irradiation cohort (re-RT cases) compared to whole reference cohort (registry) and subgroups of reference cohort divided by dose to the larynx (Figure A1a,b) and dose to the parotid glands (Figure A1c,d). (a) All dysphagia grade $\geq 3$. (b) Late dysphagia grade $\geq 3$. (c) All trismus grade $\geq 3$. (d) Late trismus grade $\geq 3$. Abbreviations: AE—adverse event, re-RT—re-irradiation, RT—radiotherapy, perc—percentile.

\section{References}

1. Overgaard, J.; Hansen, H.S.; Specht, L.; Overgaard, M.; Grau, C.; Andersen, E.; Bentzen, J.; Bastholt, L.; Hansen, O.; Johansen, J.; et al. Five compared with six fractions per week of conventional radiotherapy of squamous-cell carcinoma of head and neck: DAHANCA 6 and 7 randomised controlled trial. Lancet 2003, 362, 933-940. [CrossRef]

2. Farrag, A.; Voordeckers, M.; Tournel, K.; De Coninck, P.; Storme, G. Pattern of failure after helical tomotherapy in head and neck cancer. Strahlenther. Onkol. 2010, 186, 511-516. [CrossRef]

3. Pagh, A.; Grau, C.; Overgaard, J. Failure pattern and salvage treatment after radical treatment of head and neck cancer. Acta Oncol. 2016, 55, 625-632. [CrossRef]

4. Goodwin, W.J., Jr. Salvage surgery for patients with recurrent squamous cell carcinoma of the upper aerodigestive tract: When do the ends justify the means? Laryngoscope 2000, 110, 1-18. [CrossRef] 
5. Ward, M.C.; Riaz, N.; Caudell, J.J.; Dunlap, N.E.; Isrow, D.; Zakem, S.J.; Dault, J.; Awan, M.J.; Vargo, J.A.; Heron, D.E.; et al. Refining Patient Selection for Reirradiation of Head and Neck Squamous Carcinoma in the IMRT Era: A Multi-institution Cohort Study by the MIRI Collaborative. Int. J. Radiat. Oncol. Biol. Phys. 2018, 100, 586-594. [CrossRef]

6. Ho, J.C.; Phan, J. Reirradiation of head and neck cancer using modern highly conformal techniques. J. Sci. Spec. Head Neck 2018, 40, 2078-2093. [CrossRef]

7. Curtis, K.K.; Ross, H.J.; Garrett, A.L.; Jizba, T.A.; Patel, A.B.; Patel, S.H.; Wong, W.W.; Halyard, M.Y.; Ko, S.J.; Kosiorek, H.E.; et al. Outcomes of patients with loco-regionally recurrent or new primary squamous cell carcinomas of the head and neck treated with curative intent reirradiation at Mayo Clinic. Radiat. Oncol. 2016, 11, 55. [CrossRef]

8. Duprez, F.; Berwouts, D.; Madani, I.; Bonte, K.; Boterberg, T.; De Gersem, W.; Deron, P.; Huvenne, W.; De Neve, W. High-dose reirradiation with intensity-modulated radiotherapy for recurrent head-and-neck cancer: Disease control, survival and toxicity. Radiother. Oncol. 2014, 111, 388-392. [CrossRef]

9. Leong, Y.H.; Soon, Y.Y.; Lee, K.M.; Wong, L.C.; Tham, I.W.K.; Ho, F.C.H. Long-term outcomes after reirradiation in nasopharyngeal carcinoma with intensity-modulated radiotherapy: A meta-analysis. Head Neck 2018, 40, 622-631. [CrossRef]

10. Sulman, E.P.; Schwartz, D.L.; Le, T.T.; Ang, K.K.; Morrison, W.H.; Rosenthal, D.I.; Ahamad, A.; Kies, M.; Glisson, B.; Weber, R.; et al. IMRT reirradiation of head and neck cancer-disease control and morbidity outcomes. Int. J. Radiat. Oncol. Biol. Phys. 2009, 73, 399-409. [CrossRef]

11. Strojan, P.; Beitler, J.J.; Silver, C.E.; Mendenhall, W.M.; Shaha, A.R.; Rinaldo, A.; Takes, R.P.; Ferlito, A. When is re-irradiation in head and neck squamous cell carcinoma not indicated? Eur. Arch. Otorhinolaryngol. 2014, 271, 3107-3109. [CrossRef]

12. Strojan, P.; Corry, J.; Eisbruch, A.; Vermorken, J.B.; Mendenhall, W.M.; Lee, A.W.; Haigentz, M., Jr.; Beitler, J.J.; De Bree, R.; Takes, R.P.; et al. Recurrent and second primary squamous cell carcinoma of the head and neck: When and how to reirradiate. Head Neck 2015, 37, 134-150. [CrossRef]

13. Ward, M.C.; Lee, N.Y.; Caudell, J.J.; Zajichek, A.; Awan, M.J.; Koyfman, S.A.; Dunlap, N.E.; Zakem, S.J.; Hassanzadeh, C.; Marcrom, S.; et al. A competing risk nomogram to predict severe late toxicity after modern re-irradiation for squamous carcinoma of the head and neck. Oral Oncol. 2019, 90, 80-86. [CrossRef] [PubMed]

14. Tanvetyanon, T.; Padhya, T.; McCaffrey, J.; Zhu, W.; Boulware, D.; Deconti, R.; Trotti, A. Prognostic factors for survival after salvage reirradiation of head and neck cancer. J. Clin. Oncol. 2009, 27, 1983-1991. [CrossRef] [PubMed]

15. Hoebers, F.; Heemsbergen, W.; Moor, S.; Lopez, M.; Klop, M.; Tesselaar, M.; Rasch, C. Reirradiation for head-and-neck cancer: Delicate balance between effectiveness and toxicity. Int. J. Radiat. Oncol. Biol. Phys. 2011, 81, e111-e118. [CrossRef] [PubMed]

16. Takiar, V.; Garden, A.S.; Ma, D.; Morrison, W.H.; Edson, M.; Zafereo, M.E.; Gunn, G.B.; Fuller, C.D.; Beadle, B.; Frank, S.J.; et al. Reirradiation of Head and Neck Cancers With Intensity Modulated Radiation Therapy: Outcomes and Analyses. Int. J. Radiat. Oncol. Biol. Phys. 2016, 95, 1117-1131. [CrossRef] [PubMed]

17. Bots, W.T.C.; van den Bosch, S.; Zwijnenburg, E.M.; Dijkema, T.; van den Broek, G.B.; Weijs, W.L.J.; Verhoef, L.C.G.; Kaanders, J.H.A.M. Reirradiation of head and neck cancer: Long-term disease control and toxicity. Head Neck 2017, 39, 1122-1130. [CrossRef] [PubMed]

18. Garg, S.; Kilburn, J.M.; Lucas, J.T., Jr.; Randolph, D.; Urbanic, J.J.; Hinson, W.H.; Kearns, W.T.; Porosnicu, M.; Greven, K. Reirradiation for second primary or recurrent cancers of the head and neck: Dosimetric and outcome analysis. Head Neck 2016, 38, E961-E969. [CrossRef]

19. Lee, J.Y.; Suresh, K.; Nguyen, R.; Sapir, E.; Dow, J.S.; Arnould, G.S.; Worden, F.P.; Spector, M.E.; Prince, M.E.; McLean, S.A.; et al. Predictors of severe long-term toxicity after re-irradiation for head and neck cancer. Oral Oncol. 2016, 60, 32-40. [CrossRef]

20. Dionisi, F.; Fiorica, F.; D’Angelo, E.; Maddalo, M.; Giacomelli, I.; Tornari, E.; Rosca, A.; Vigo, F.; Romanello, D.; Cianchetti, M.; et al. Organs at risk's tolerance and dose limits for head and neck cancer re-irradiation: A literature review. Oral Oncol. 2019, 98 , 35-47. [CrossRef] [PubMed]

21. Emami, B.; Lyman, J.; Brown, A.; Coia, L.; Goitein, M.; Munzenrider, J.E.; Shank, B.; Solin, L.J.; Wesson, M. Tolerance of normal tissue to therapeutic irradiation. Int. J. Radiat. Oncol. Biol. Phys. 1991, 21, 109-122. [CrossRef]

22. Nieder, C.; Grosu, A.L.; Andratschke, N.H.; Molls, M. Update of human spinal cord reirradiation tolerance based on additional data from 38 patients. Int. J. Radiat. Oncol. Biol. Phys. 2006, 66, 1446-1449. [CrossRef]

23. McDonald, M.W.; Moore, M.G.; Johnstone, P.A. Risk of carotid blowout after reirradiation of the head and neck: A systematic review. Int. J. Radiat. Oncol. Biol. Phys. 2012, 82, 1083-1089. [CrossRef]

24. Embring, A.; Onjukka, E.; Mercke, C.; Lax, I.; Berglund, A.; Bornedal, S.; Wennberg, B.; Friesland, S. Overlapping volumes in re-irradiation for head and neck cancer-An important factor for patient selection. Radiat. Oncol. 2020, 15, 147. [CrossRef]

25. Ruifrok, A.C.; van der Kogel, A.J. A "reappraisal" of the LQ model for the understanding of dose-fractionation in radiotherapy. Int. J. Radiat. Oncol. Biol. Phys. 1993, 25, 926-929. [CrossRef]

26. LENT SOMA tables. Radiot. Oncol. 1995, 35, 17-60. [CrossRef]

27. Cox, J.D.; Stetz, J.; Pajak, T.F. Toxicity criteria of the Radiation Therapy Oncology Group (RTOG) and the European Organization for Research and Treatment of Cancer (EORTC). Int. J. Radiat. Oncol. Biol. Phys. 1995, 31, 1341-1346. [CrossRef]

28. Hammerlid, E.; Haugen Cange, H.; Söderström, K.; Brun, E.; Farnebo, L.; Olin, M.; Högmo, A.; Sjödin, H.; on behalf of Regionalt Cancercentrum. Nationellt Vårdprogram Huvud_och Halscancer (National Guidelines for Head and Neck Cancer). 2019. Available online: https:/ / kunskapsbanken.cancercentrum.se/diagnoser/huvud-och-halscancer/vardprogram/behandlingvid-huvud-och-halscancer/\#chapter-9-2-Onkologisk-behandling (accessed on 23 June 2021). 
29. Jensen, K.; Friborg, J.; Hansen, C.R.; Samsoe, E.; Johansen, J.; Andersen, M.; Smulders, B.; Andersen, E.; Nielsen, M.S.; Eriksen, J.G.; et al. The Danish Head and Neck Cancer Group (DAHANCA) 2020 radiotherapy guidelines. Radiot. Oncol. 2020, 151, 149-151. [CrossRef]

30. Pfeister, D.; Spencer, S.; Brizel, D.; Busse, P.; Caudell, J.; Cmelak, A.; Foote, R.; Galloway, T.; Hitchcock, Y.; Mell, L.; et al. Head and Neck Cancers. NCCN Clinical Practice Guidelines in Oncology. National Comprehensive Cancer Network, 2021. Available online: https://jnccn.org/view/journals/jnccn/18/7/article-p873.xml(accessed on 23 June 2021).

31. Caudell, J.J.; Ward, M.C.; Riaz, N.; Zakem, S.J.; Awan, M.J.; Dunlap, N.E.; Isrow, D.; Hassanzadeh, C.; Vargo, J.A.; Heron, D.E.; et al. Volume, Dose, and Fractionation Considerations for IMRT-based Reirradiation in Head and Neck Cancer: A Multi-institution Analysis. Int. J. Radiat. Oncol. Biol. Phys. 2018, 100, 606-617. [CrossRef] [PubMed]

32. Phan, J.; Sio, T.T.; Nguyen, T.P.; Takiar, V.; Gunn, G.B.; Garden, A.S.; Rosenthal, D.I.; Fuller, C.D.; Morrison, W.H.; Beadle, B.; et al. Reirradiation of Head and Neck Cancers With Proton Therapy: Outcomes and Analyses. Int. J. Radiat. Oncol. Biol. Phys. 2016, 96, 30-41. [CrossRef] [PubMed]

33. Olteanu, L.A.M.; Duprez, F.; De Neve, W.; Berwouts, D.; Vercauteren, T.; Bauters, W.; Deron, P.; Huvenne, W.; Bonte, K.; Goethals, I.; et al. Late mucosal ulcers in dose-escalated adaptive dose-painting treatments for head-and-neck cancer. Acta Oncol. 2018, 57, 262-268. [CrossRef] [PubMed]

34. van der Geer, S.J.; van Rijn, P.V.; Kamstra, J.I.; Langendijk, J.A.; van der Laan, B.; Roodenburg, J.L.N.; Jan, L.N.; Dijkstra, P.U. Prevalence and prediction of trismus in patients with head and neck cancer: A cross-sectional study. Head Neck 2019, 41, 64-71. [CrossRef] [PubMed] 